\title{
Obtention of Nanostructured Silica Glass by Sol-Gel Process with Incorporation of Lead Compounds
}

\author{
Ana Maria M. Santos ${ }^{\mathrm{a}}$, Wander L. Vasconcelos ${ }^{\mathrm{b}}$ \\ ${ }^{\mathrm{a}}$ Centro de Desenvolvimento da Tecnologia Nuclear - CDTN/CNEN \\ Rua Mário Werneck s/n, 31120-970 Pampulha Belo Horizonte - MG, Brazil \\ ${ }^{\mathrm{b}}$ Departamento de Engenharia Metalúrgica e de Materiais, UFMG \\ Rua Espírito Santo, 35 - 2andar - Centro, 30160-030 Belo Horizonte - MG, Brazil
}

Received: August 15, 1998; Revised: March 30, 1999

\begin{abstract}
The methodology of obtention of nanostructured glass, incorporated with lead compounds, obtained by sol-gel processing and the structural characterizations are presented. Specific surface area, porosity, pore morphology and pore size distributions of the gels were characterized with nitrogen sorption (BET) and mercury pycnometry. The pore size distributions of gels obtained using lead nitrate were more narrow than the ones observed for gels made with lead acetate. It was also observed the presence of a bimodal pore size distribution for gels produced using lead nitrate.
\end{abstract}

Keywords: sol-gel process, nanostructured silica glass, incorporation

\section{Introduction}

The complexity of the sol-gel process provides an enormous potential for producing new types of materials with specific properties, which are difficult or impossible to obtain using the traditional ways. Besides obtaining high homogeneity and purity of final products, the sol-gel method allows the structure to be controlled in a molecular scale, being totally open to incorporate other phases and the composition, density and pore morphology can be changed at various stages ${ }^{1,2}$.

In the scope of development of a matrix for incorporation of waste aggressive to the environment, the sol-gel process appears as an alternative. This is due to the possibility of permitting the structural control of the matrix during intermediate stages, which is carried out through the control of process variables such as water to alkoxide molar ratio, concentration and type of catalyst, reaction sequence, etc $^{3}$.

The aim of this work is to study the incorporation of lead compounds into a silica matrix employing sol-gel process. The gels were synthesized through hydrolysis and condensation of tetramethylorthosilicate (TMOS) under atmospheric pressure. The nitrogen sorption and mercury pycnometry techniques were employed to characterize the structure of silica gels. Specific surface area, porosity and

ae-mail: amms@urano.cdtn.br; fax: (031) 4993390

be-mail:wlv@urano.cdtn.br pore size distributions of the gels were obtained. The porous morphology is inferred by nitrogen sorption-desorption isotherms.

\section{Experimental}

The gels were synthesized by sol-gel process with hydrolysis and condensation of tetramethylorthosilicate catalyzed by dilute aqueous solution with nitric acid. Lead nitrate $\left(\mathrm{Pb}\left(\mathrm{NO}_{3}\right)_{2}\right)$ and lead acetate $\left(\mathrm{Pb}\left(\mathrm{CH}_{3} \mathrm{COO}\right)_{2} .3 \mathrm{H}_{2} \mathrm{O}\right)$ were used as incorporation components. The sequence of the sol-gel process used in this work were: mixing the aqueous solution with TMOS, casting, gelation, aging, drying and heat treatment.

The molar ratio water to TMOS was 16 , the final $\mathrm{pH}$ ranged between 1.5 and 4.0 and the lead weight content (in the casting solution) varied between $0.2 \%$ to $5.3 \%$. The sols were cast and gelled inside plastic containers at room temperature. Subsequently, the gels were aged at $60{ }^{\circ} \mathrm{C}$ during $48 \mathrm{~h}$ and dried at $105{ }^{\circ} \mathrm{C}$ for $48 \mathrm{~h}$. After drying, the gels were heat treated at $900{ }^{\circ} \mathrm{C}$ and $1000{ }^{\circ} \mathrm{C}$. In this work, gelation time was defined as the period between casting and the moment in which the material stopped flowing inside the container when it was tilted. 


\section{Results and Discussion}

The gelation times for gels obtained using lead nitrate presented a time period measured in days, while for gels made with lead acetate the gelation times could be expressed in hours. For gels obtained using lead nitrate, under acidic conditions $(\mathrm{pH}=1.5)$, the hydrolysis rate exceeds the condensation rate, resulting in weakly branched structure and relatively long gelation times. For gels obtained using lead acetate, under less acidic conditions $(\mathrm{pH}=4)$, the condensation rate increased and the hydrolysis rate decreased, resulting in shorter gelation times.

A typical dried gel cylinder was $13 \mathrm{~mm}$ height and 12.6 $\mathrm{mm}$ in diameter and it was not fragmented. Some gels heat treated at $900{ }^{\circ} \mathrm{C}$ and $1000{ }^{\circ} \mathrm{C}$ were broken.

Figures 1 and 2 present respectively the results of bulk density and specific surface area as a function of lead content for two $\mathrm{pH}$ ranges (variation about 0.5), while Figs. 3, 4, 5 and 6 show sorption-desorption isotherms and Figs. 7,8 and 9 show the results of pore size distribution analyses. The lead content showed in these figures refer to lead content in the casting solution.

The bulk densities of the gels were measured using Arquimedes' method and mercury as media. At least three measurements were made per sample. The results are shown in Fig. 1. The bulk density increases with lead content, independently of the salt type used.

The specific surface area was measured by nitrogen sorption using the single point method as described in $^{4}$. Figure 2 presents the results of specific surface area as a function of the lead content. As one can seen in Fig. 2, the specific surface area decreases as the lead content increases and, for the same $\mathrm{pH}$ value, it was observed no significant difference in the results between the type of lead salt used. There is a sharp drop in surface area with lead content in

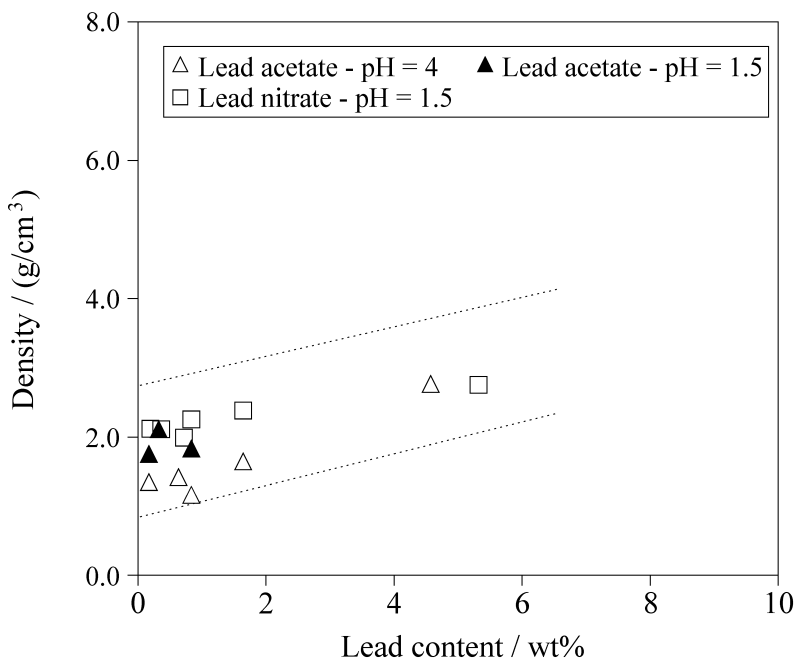

Figure 1. Bulk density as a function of lead content. the case of gels obtained using lead acetate at $\mathrm{pH} 4$. It can also be seen in Fig. 2 the influence of $\mathrm{pH}$ in the specific surface area, which was also observed in references ${ }^{5,6}$. The $\mathrm{pH}$ influence can also be observed through the density results shown in Fig. 1. The decrease on surface area with the addition of dopants was also observed by Ganguli ${ }^{7}$.

The evaluation of the pore size distribution and the pore morphology were carried out from nitrogen sorption isotherms. The pore size distribution was determined by applying the Kelvin equation to the desorption branch of the isotherms. The pore morphology could be inferred using the de Boer work ${ }^{4}$. de Boer idealized five types of the hysteresis for relative pressure above 0.3 and associated the shape of the pores with the form of hysteresis curves (Fig. 10). Table 1 shows the association between hysteresis form and the geometrical shape of the pore. A more detailed description is given in reference ${ }^{4}$.

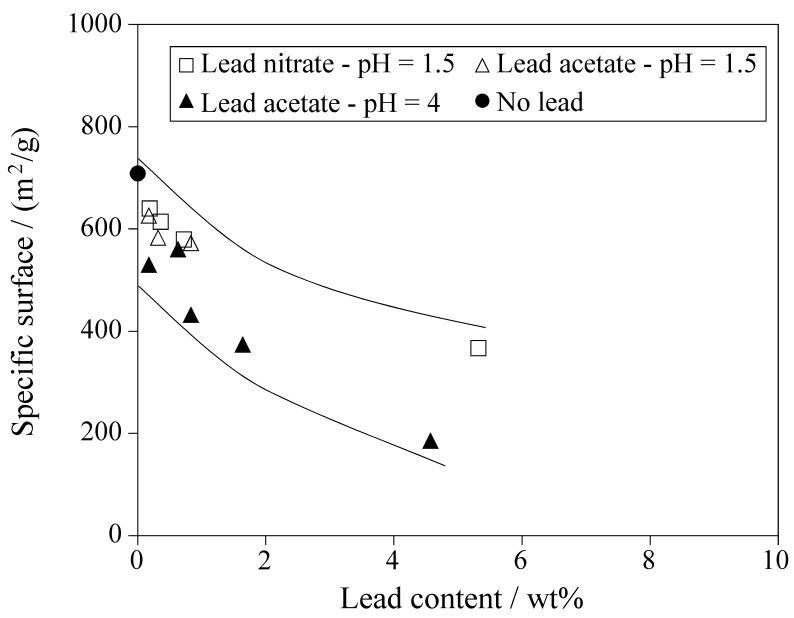

Figure 2. Specific surface area as a function of lead content.

Table 1. Correlation between the type of hysteresis and pore shape, according to de Boer ${ }^{4}$.

\begin{tabular}{|c|c|c|}
\hline Hysteresis & Geometric Shape & Examples \\
\hline a & $\begin{array}{l}\text { Cylindrical pores open at } \\
\text { both ends }\end{array}$ & \\
\hline $\mathrm{b}$ & $\begin{array}{l}\text { Slit-shaped pores or the } \\
\text { space between parallel plates }\end{array}$ & \\
\hline $\mathrm{c}$ & $\begin{array}{l}\text { Wedge-shaped pores with } \\
\text { open ends }\end{array}$ & \\
\hline d & $\begin{array}{l}\text { Wedge-shaped pores with } \\
\text { narrow necks at one or both } \\
\text { open ends }\end{array}$ & $E$ \\
\hline $\mathrm{e}$ & $\begin{array}{l}\text { Cylindrical pores with large } \\
\text { central volume and strangled } \\
\text { ends ("bottle-neck") }\end{array}$ & \\
\hline
\end{tabular}


From Fig. 3 to Fig. 6, typical results of sorption-desorption isotherms are shown for gels incorporated by lead nitrate and lead acetate. In these figures, it can be observed that the isotherm forms varies with lead content for gels obtained by lead acetate when heat treated at $900{ }^{\circ} \mathrm{C}$. It can also be seen in these figures, that the shape of the isotherms, with different lead content, can be associated with hysteresis curves type (a) and (e) (Fig. 10), both associated with pores of cylindrical shape.

Figures 7 and 8 present typical results of pore size distributions of gels obtained from lead nitrate and lead acetate, both heat treated at $105^{\circ} \mathrm{C}$. It can be observed, in these figures, that the pore size distribution of gels obtained using lead nitrate (Fig. 8) showed a narrow pore size distribution and a bimodal curve when compared with the pore size distribution of gels obtained using lead acetate.

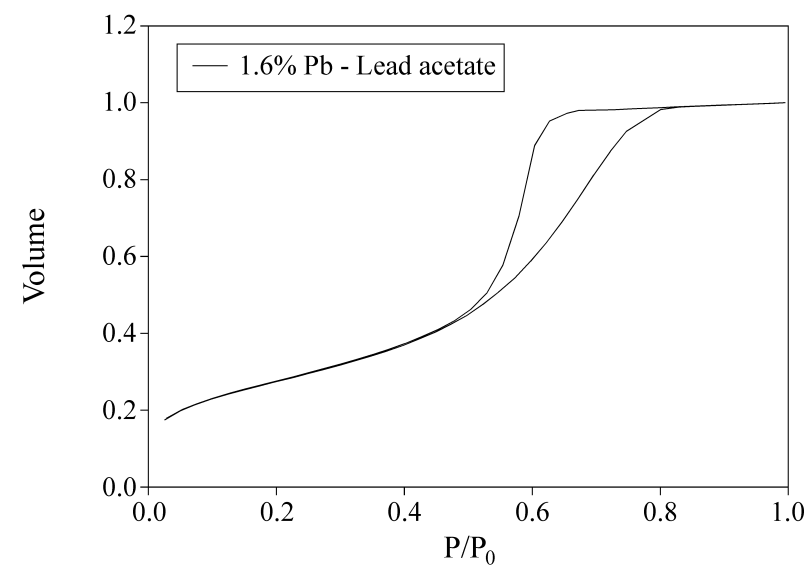

Figure 3. Sorption-desorption isotherm of gel obtained via lead acetate, heat treated at $105{ }^{\circ} \mathrm{C}$ (the weight of the sample was not considered, then volume scale is relative).

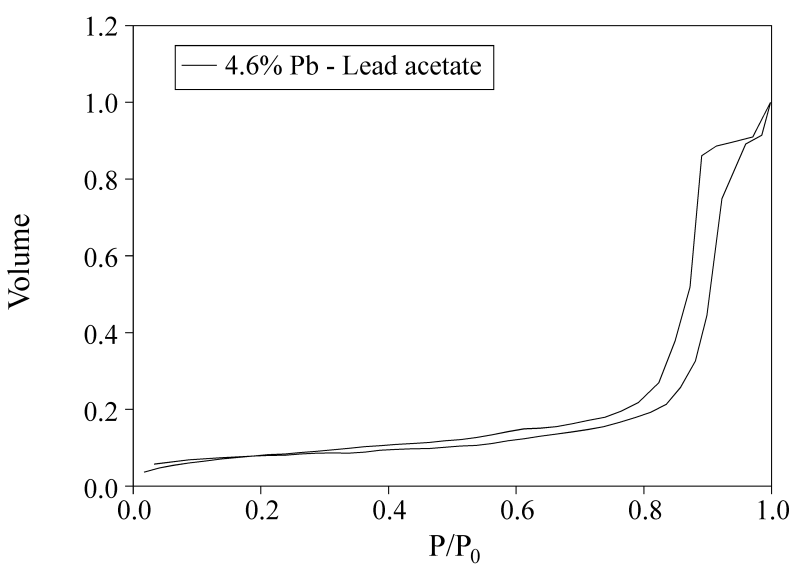

Figure 4. Sorption-desorption isotherm of gel obtained via lead acetate, heat treated at $900{ }^{\circ} \mathrm{C}$ (the weight of the sample was not considered, then volume scale is relative).

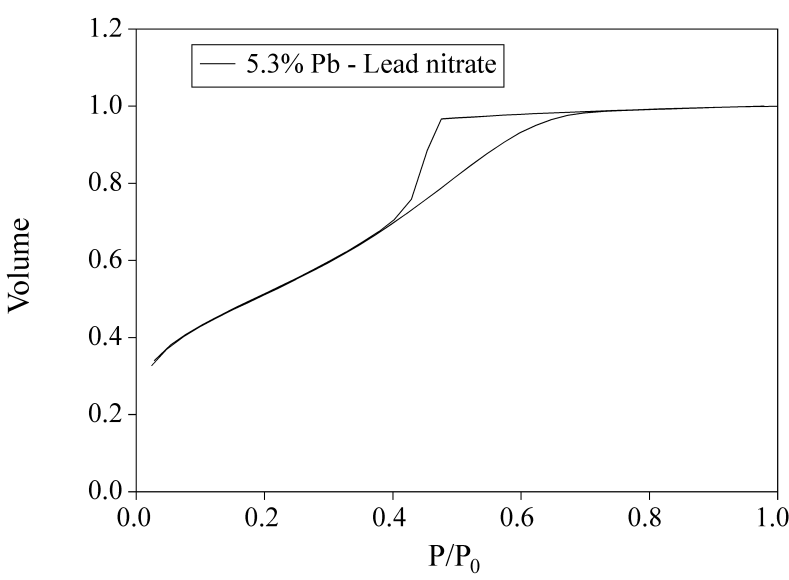

Figure 5. Sorption-desorption isotherm of gel obtained via lead nitrate, heat treated at $105^{\circ} \mathrm{C}$ (the weight of the sample was not considered, then volume scale is relative).

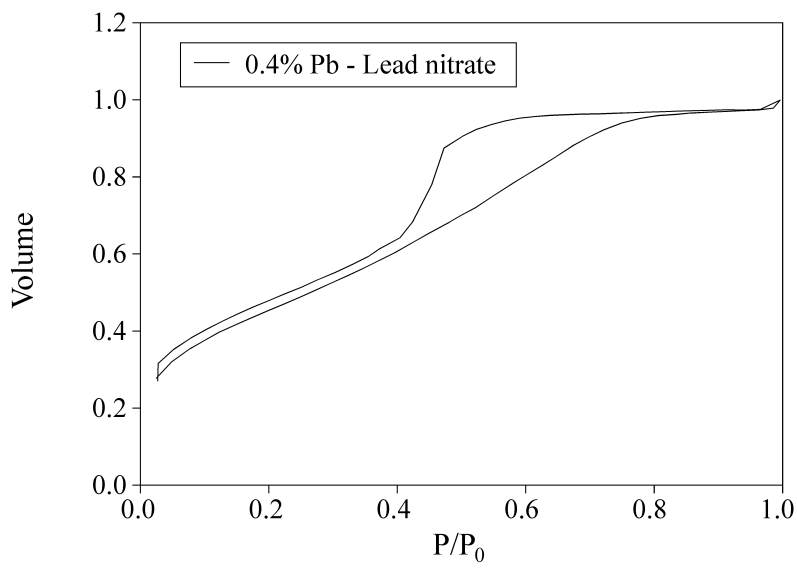

Figure 6. Sorption-desorption isotherm of gel obtained via lead nitrate, heat treated at $900^{\circ} \mathrm{C}$ (the weight of the sample was not considered, then volume scale is relative).

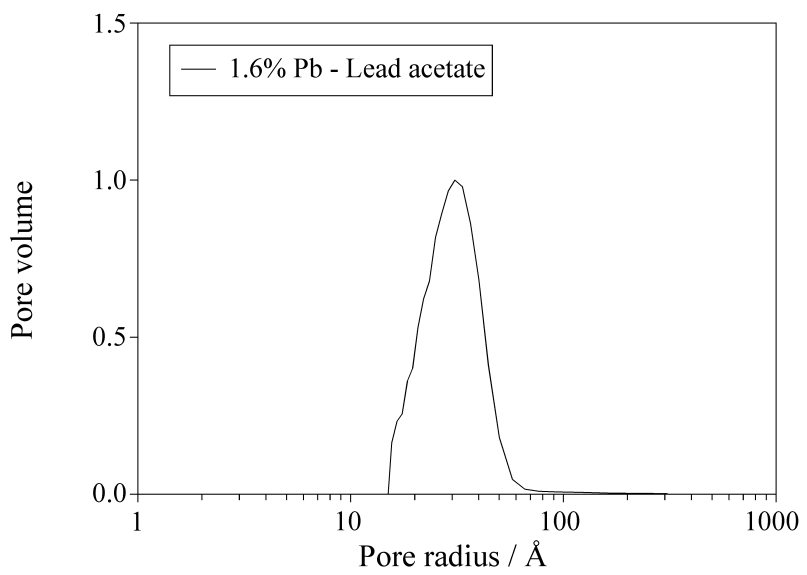

Figure 7. Pore size distribution of gel obtained via lead acetate heat treated at $105{ }^{\circ} \mathrm{C}$ (the weight of the sample was not considered, then volume scale is relative). 


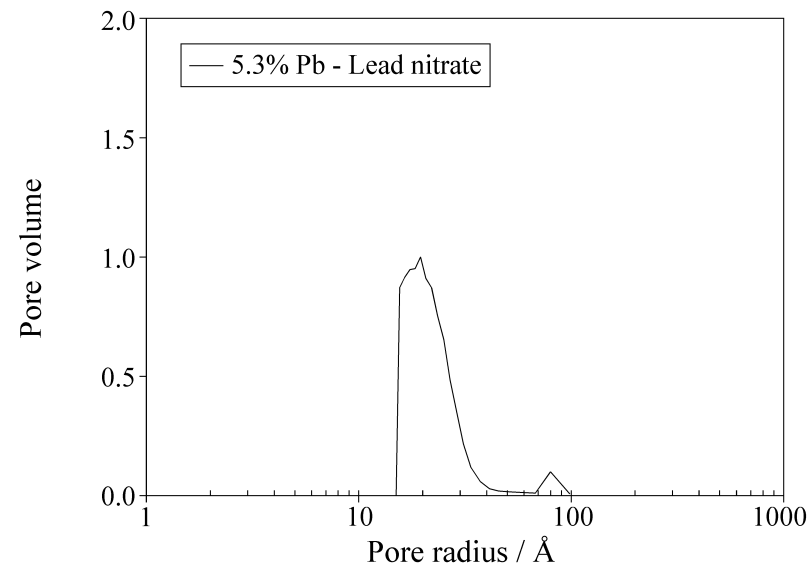

Figure 8. Pore size distribution of gel obtained via lead nitrate heat treated at $105^{\circ} \mathrm{C}$ (the weight of the sample was not considered, then volume scale is relative).

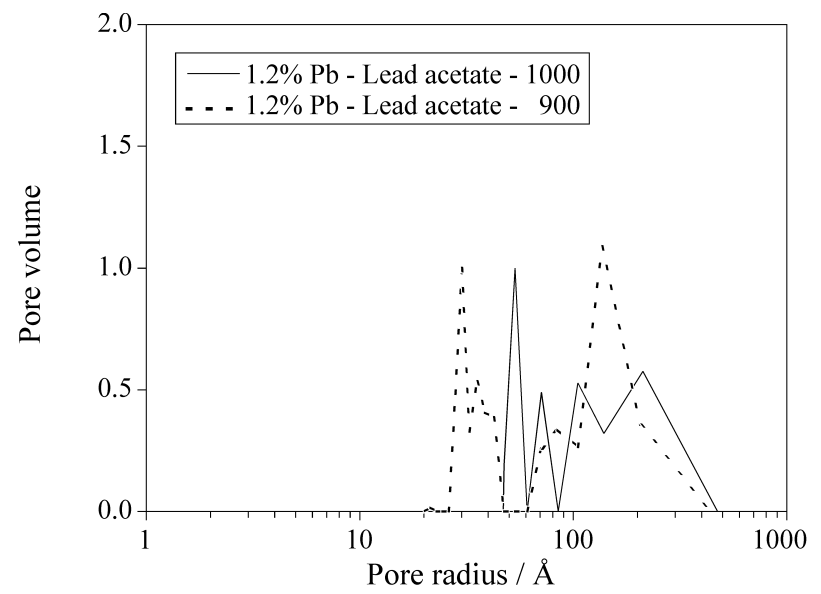

Figure 9. Pore size distribution of gel obtained via lead acetate heat treated at $900{ }^{\circ} \mathrm{C}$ and $1000{ }^{\circ} \mathrm{C}$ (the weight of the sample was not considered, then volume scale is relative).

This bimodal behavior was also observed by Ganguli ${ }^{7}$, for gels obtained with TEOS and dopped with $\mathrm{Al}^{3+} \mathrm{e} \mathrm{Cr}^{3+}$.

Pore size distributions in gels obtained via lead acetate, heat treated at $900{ }^{\circ} \mathrm{C}$ and at $1000{ }^{\circ} \mathrm{C}$, with $1.2 \mathrm{wt} \% \mathrm{~Pb}$ (in casting solution), presented large scattering (see Fig. 9).

\section{Conclusion}

The lead incorporation into silica matrix using sol-gel process by direct mixture of lead nitrate and lead acetate into the casting solution was investigated. It was possible to characterize the silica gels concerning specific surface area, bulk density and pore structure. From nitrogen sorp-
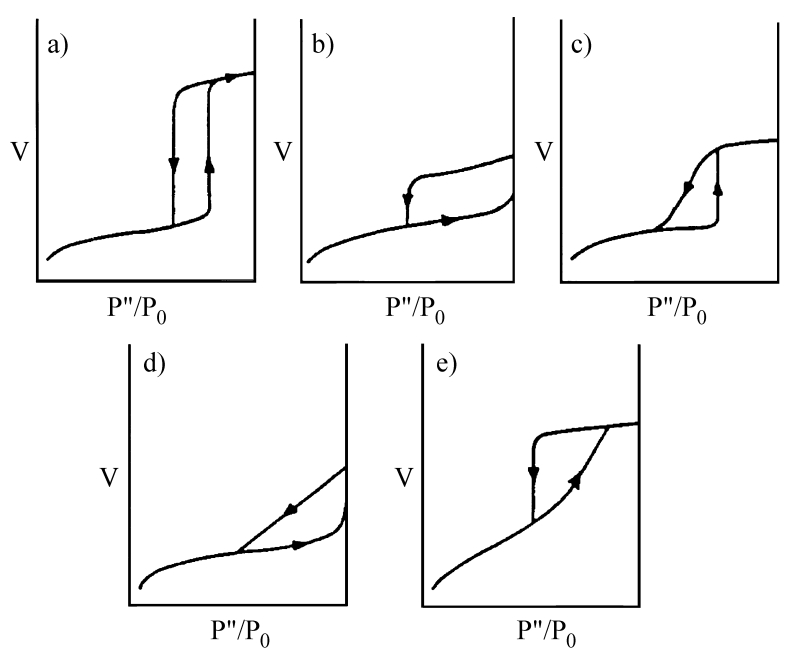

Figure 10. Types of hysteresis proposed by de Boer ${ }^{4}$.

tion experiments, the sorption-desorption isotherms and pore size distributions were obtained. The cylindrical form of pores was inferred through the hysteresis curves, based on de Boer work. The pore size distributions of gels obtained using lead nitrate were more narrow than the ones observed for gels made with lead acetate. It was also observed the presence of a bimodal distribution for gels produced using lead nitrate.

\section{Acknowledgments}

The authors are grateful for the financial support of CNPq.

\section{References}

1. Ulrich, D.R. Journal of Non-Crystalline Solids, v. 100, p. 174-193, 1988.

2. Hench, L.L.; Wang, S.H. Phase Transitions, v. 24-26, p. 785-834, 1990.

3. Hench, L.L.; West, J.K. Chemical Review, v. 90, p. 33-72, 1990.

4. Dullien, F.A.L. Porous Media Fluid Transport and Pore Structure. 2 ed. Academic Press, 1991.

5. Titulaer, M.K. et al. Journal of Non-Crystalline Solids, v. 170, p. 113-127, 1994.

6. Rubio, F.; Rubio, J.; Oteo, J.L. Journal of Sol-Gel Science and Technology, v. 8, p. 159-163, 1997.

7. Ganguli, D. Journal of Non-Crystalline Solids, v. 101, p. 117-119, 1988. 